\title{
Correction to: Photo- and temperature-dependent formation of tryptophan/silver nanoparticles
}

\author{
lu. Mukha' $\cdot$ N. Vityuk' ${ }^{1}$ A. Khodko² $\cdot$ N. Kachalova ${ }^{2,4} \cdot$ O. Fedyshyn ${ }^{3}$. \\ M. Malysheva ${ }^{3} \cdot$ A. Eremenko $^{1}$
}

Published online: 8 July 2019

(c) Springer Nature B.V. 2019

\section{Correction to: Research on Chemical Intermediates https://doi.org/10.1007/s11164-019-03890-5}

In the original publication of the article, the co-author's name was incorrectly published as "O. N. Kachalova". However, it should be "N. Kachalova".

The original article has been corrected.

Publisher's Note Springer Nature remains neutral with regard to jurisdictional claims in published maps and institutional affiliations.

The original article can be found online at https://doi.org/10.1007/s11164-019-03890-5.

Iu. Mukha

iu.mukha@gmail.com

A. Khodko

khodkoalina@gmail.com

N. Kachalova

kachalova.nataliya@gmail.com

M. Malysheva

maria_malysheva@univ.kiev.ua

1 Chuiko Institute of Surface Chemistry, NAS of Ukraine, 17 General Naumov Str., Kiev 03164, Ukraine

2 Institute of Physics, NAS of Ukraine, pr. Nauky, 46, Kiev 03039, Ukraine

3 Department of Chemistry, Taras Shevchenko National University of Kyiv, 64 Volodymyrska Str., Kiev 01601, Ukraine

4 L.M. Litvinenko Institute of Physical - Organic and Coal Chemistry, NAS of Ukraine, 40 Kharkivske Shose Av, Kiev 02160, Ukraine 